\title{
Desenvolvimento e crescimento populacional de Alabama argillacea em algodoeiro de fibra branca e colorida
}

\author{
Roberta Leme dos Santos(1), Jorge Braz Torres ${ }^{(1)}$ e Cristina Schettino Bastos ${ }^{(2)}$
}

\begin{abstract}
(1)Universidade Federal Rural de Pernambuco, Departamento de Agronomia/Entomologia, Avenida Dom Manoel de Medeiros, $s / n$ o , Dois Irmãos, CEP 52171-900 Recife, PE. E-mail: robertaleme2@uol.com.br, jtorres@depa.ufrpe.br (2)Embrapa Algodão, Rua Osvaldo Cruz, no 1143, Centenário, CEP 58107-720 Campina Grande, PB. E-mail: cristina.bastos@embrapa.br
\end{abstract}

Resumo - O objetivo deste trabalho foi avaliar o desenvolvimento e a reprodução do curuquerê-do-algodoeiro [Alabama argillacea (Hübner)], em cultivares de algodoeiro de fibras branca (BRS 201 e Acala 90) e verde (BRS Verde). O experimento consistiu de três tratamentos (cultivares), com dez repetições em laboratório e oito em campo, em delineamento inteiramente casualizado. Em laboratório, as lagartas do curuquerê foram alimentadas com folhas das cultivares, enquanto no campo, as posturas foram confinadas sobre as plantas e monitoradas até completar a geração. A cultivar BRS 201 ocasionou: prolongamento da fase larval de dois dias, em comparação às outras cultivares, em laboratório e no campo; menor sobrevivência da fase larval, em laboratório; menor peso de pupas e produção de ovos, em laboratório e campo. O crescimento populacional do curuquerê-do-algodoeiro, estimado após quatro gerações sucessivas, mostrou que uma fêmea fertilizada tem capacidade de produzir 1.776,6, 47,19 e 6,51 indivíduos em Acala 90, BRS Verde e BRS 201, respectivamente. O menor desempenho no desenvolvimento e na reprodução do curuquerê, criado na cultivar BRS 201, é importante no controle desta praga no campo.

Termos para indexação: Gossypium hirsutum, algodão colorido, curuquerê-do-algodoeiro, resistência de plantas.

\section{Development and population growth of Alabama argillacea on cotton of white and colored fibers}

\begin{abstract}
The aim of this work was to evaluate the developmental rates and reproductive output of the cotton leafworm [Alabama argillacea (Hübner)], fed on leaves of cultivars with white fibers (BRS 201 and Acala 90) and colored ones (BRS Verde). The experiment was conducted in a completely randomized design, with three treatments (cultivars) and ten and eight replications in laboratory and in field, respectively. In the laboratory, larvae were fed with cotton leaves, while in the field, eggs were caged on plant terminals and monitored until one generation was completed. Compared to the other cultivars, BRS 201 caused, both in laboratory and in the field: prolongation of larval development of A. argillacea in about two days; and lower pupal weight and egg production. In laboratory, the cotton leafworm reared on BRS 201 showed the lower survival index (46\%). Population growth of A. argillacea estimated after four successive generations showed that one fertilized female has the potential for producing 1,776.6, 47.19 and 6.51 individuals colonizing Acala 90, BRS Verde and BRS 201, respectively. Lower performance in development and reproduction of cotton leafworm fed on BRS 201 can offer additional control to this pest in the field.
\end{abstract}

Index terms: Gossypium hirsutum, colored cotton fiber, cotton leafworm, host plant resistance.

\section{Introdução}

O algodoeiro (Gossypium hirsutum) é uma das principais culturas que contribuem para o crescimento do agronegócio brasileiro. Embora o cultivo do algodoeiro se caracterize por grandes lavouras na Região CentroOeste do Brasil, com $80 \%$ da produção nacional (Conab, 2007), no Semi-Árido do Nordeste o cultivo do algodão é feito por pequenos e médios produtores e tem sido, recentemente, impulsionado pelo plantio de cultivares de algodão de fibra colorida (Jornal da Abrapa, 2006).

Apesar da expressividade da cotonicultura, o seu grande desafio é manter alto rendimento em produtividade, conciliado com a busca da menor relação custo/benefício e com a sustentabilidade da atividade agrícola no Semi-Árido. Observa-se que entre os 
principais limitantes para isso estão a disponibilidade e o uso de tecnologias apropriadas para o manejo de pragas, durante os estágios fenológicos da cultura. A produção do algodoeiro pode ser significativamente reduzida pela ocorrência de pragas desfolhadoras, cujas táticas de manejo dessas pragas incluem o controle biológico, o uso de cultivares resistentes, o controle cultural, o controle químico e outros (Ramalho, 1994). Entre essas táticas, o uso de cultivares resistentes se destaca pela compatibilidade com a maioria das outras táticas de manejo empregadas (Bottrell et al., 1998). Entretanto, novas cultivares de algodoeiro estão sendo selecionadas para oferecer, principalmente, aumento de produtividade e adaptação ao ambiente onde serão cultivadas, embora muitas não sejam resistentes às pragas, ou não se tenha informação sobre sua resistência. Recentemente, por exemplo, cultivares de algodoeiro de fibra colorida têm sido disponibilizadas para os produtores, em especial, aos pequenos agricultores no Nordeste do Brasil. Independentemente das cultivares e sistema de cultivos utilizados, o algodoeiro pode ser infestado por diversas pragas e, entre elas, destaca-se o curuquerê, que é a praga desfolhadora de maior importância na cultura (Ramalho, 1994; Soares et al., 1997). O curuquerê pode ocorrer desde a fase inicial à maturação da lavoura e em todas as regiões onde se tem cultivado o algodoeiro no Brasil (Quirino \& Soares, 2001; Soares \& Silva, 2003) e, freqüentemente, atinge o nível de controle (Domiciano $\&$ Santos, 1994).

Diferentes cultivares de algodoeiro têm apresentado certo grau de resistência ao ataque do curuquerê-do-algodoeiro. Bleicher (1982) observou que os genótipos pesquisados pela Embrapa Algodão apresentaram maior resistência ao curuquerê-doalgodoeiro [Alabama argillacea (Hübner)]. Os genótipos CNPA 9211-31 e CNPA 9211-21 apresentaram antibiose ao desenvolvimento de A. argillacea, em relação a outros nove genótipos (Ferreira \& Lara, 1999). De acordo com Lara et al. (1999), o genótipo CNPA 9211-31 não é preferido para alimentação por lagartas de A. argillacea. Santos \& Boiça Júnior (2001) estudaram a biologia do curuquerê, em laboratório, alimentado com folhas de 11 genótipos de algodoeiro, e observaram pouca diferença na duração e na sobrevivência das fases de desenvolvimento da praga. Esses autores destacaram que o ganho de peso de lagartas e a fecundidade dos adultos foram altamente variáveis entre os genótipos estudados, e revelaram que alguns genótipos (CNPA 9211-31, CNPA 9211-41 e CNPA Precoce 1 e Precoce 2) foram menos suscetíveis ao curuquerê.

Apesar da existência de estudos sobre a resistência de cultivares de algodoeiro ao curuquerê-do-algodoeiro (Bleicher, 1982; Ferreira \& Lara, 1999; Santos \& Boiça Júnior, 2001), não são conhecidas informações sobre as cultivares de fibra branca BRS 201 e de fibra colorida BRS Verde, recomendadas para plantio no Semi-Árido do Nordeste (Araújo, 2003).

O objetivo deste trabalho foi avaliar, em laboratório e em campo, o desenvolvimento e a reprodução do curuquerê, alimentado com folhas das cultivares BRS Verde e BRS 201, em comparação à cultivar Acala 90, tida como de alta produtividade e largamente plantada no Centro-Oeste brasileiro.

\section{Material e Métodos}

O experimento foi conduzido no Laboratório de Controle Biológico e na Área Experimental do Departamento de Agronomia, da Universidade Federal Rural de Pernambuco (UFRPE), Recife, PE.

Foram utilizadas as cultivares de algodão de fibra branca Acala 90 e BRS 201, e a de fibra colorida BRS Verde.

No campo, as três cultivares foram semeadas em 5 de outubro de 2006, em três fileiras de aproximadamente $4 \mathrm{~m}$ de comprimento, com espaçamento de $0,8 \mathrm{~m}$ entre linhas e aproximadamente 0,2 m entre plantas na linha. Durante o desenvolvimento das plantas, foram realizadas três adubações de cobertura, com uréia, e capina manual de plantas daninhas. As plantas foram utilizadas no experimento entre 40 e 50 dias após emergência.

No laboratório, o experimento foi iniciado com lagartas de primeiro ínstar (com menos de 12 horas de idade) de A. argillacea, provenientes da criação mantida em laboratório. O desenvolvimento de lagartas foi monitorado com dez repetições de cinco lagartas cada, para as três cultivares. Cada repetição consistiu de uma gaiola de PVC de 14×21 cm (diâmetro interno e altura), vedada por organza fixada na parte superior por fita elástica. A base inferior da gaiola foi apoiada sobre prato de vaso de jardinagem. No interior das gaiolas, as lagartas recém-eclodidas foram transferidas, com auxílio de pincel de ponta fina, para folhas de algodoeiro coletadas do terço superior da planta. As folhas ofertadas às lagartas foram previamente lavadas, em hipoclorito 
de sódio a $10 \%$, e deixadas por cerca de 2 horas no laboratório para perder o excesso de umidade. Para manter a turgidez, as folhas foram acondicionadas em frascos de vidro de $25 \mathrm{~mL}$ com água e foram substituídas regularmente. A primeira substituição ocorreu três dias após a infestação e, posteriormente, a cada dois dias; no final do desenvolvimento da lagarta, as folhas foram substituídas diariamente. As avaliações foram realizadas, tendo-se determinado a duração e sobrevivência de lagartas, peso de pupa e produção de ovos.

No estudo de campo, foram instaladas, na fileira central de plantas de cada cultivar, oito gaiolas de $30 \times 60 \mathrm{~cm}$, confeccionadas com tecido organza, que possuíam uma extremidade fechada superior e uma extremidade inferior provida de um cordão que servia para o fechamento e abertura da gaiola e para prendêla à haste principal da planta. $\mathrm{O}$ manuseio das plantas, na parte interna da gaiola, era feito por meio de uma abertura lateral de $40 \mathrm{~cm}$ de comprimento, fechada com zíper.

Para manter as gaiolas suspensas e estendidas sobre as plantas, um fio de arame foi instalado ao longo da fileira de algodoeiro, preso a estacas instaladas nas extremidades das fileiras e esticado pouco acima das plantas. Assim, as gaiolas ficaram presas a esse fio de arame com o auxílio de pregadores, o que permitiu liberdade de crescimento da parte apical das plantas e locomoção dos insetos no interior das gaiolas.

No interior de cada gaiola, foram introduzidos 15 ovos de A. argillacea por planta. As posturas foram obtidas em papel de formulário contínuo, que havia sido exposto no interior das gaiolas de criação de adultos, em laboratório. A criação do curuquerê em laboratório, que originou os insetos para o experimento, estava na décima geração, e foi alimentada em folhas da cultivar CNPA 7H. A criação da A. argillacea foi feita com grupos de 15 a 20 lagartas por gaiola de PVC de $22 \times 17 \mathrm{~cm}$ (altura x diâmetro). Como alimento, empregaram-se ponteiros de algodão, com pecíolos mantidos em frascos com água e no interior de gaiolas. Cada gaiola tinha um anel de PVC de $17 \mathrm{~cm}$ de diâmetro e $4 \mathrm{~cm}$ de altura, fixados na parte inferior da gaiola. Entre esse anel e a gaiola havia uma tela de náilon para permitir a passagem das fezes das lagartas. A gaiola superior e o anel foram unidos com cola quente com a tela entre eles. Este conjunto, então, foi disposto sobre um prato de jardinagem, que funcionou como coletor de fezes das lagartas, e manteve, assim, a gaiola e o alimento sempre limpos. As gaiolas eram lavadas a cada geração e reutilizadas. A abertura superior das gaiolas foi vedada com tecido organza fixado por uma tira elástica. Os adultos foram mantidos em gaiolas de PVC de $22 \times 17 \mathrm{~cm}$ (altura x diâmetro), forradas internamente com papel contínuo para a coleta de posturas. A gaiola foi colocada diretamente sobre o prato de jardinagem forrado com papel-borrão. As mariposas foram alimentadas por meio de algodão, embebido em solução de mel a 10\%, disposto no interior das gaiolas em tampas de garrafa PET. A parte superior das gaiolas foi vedada com filó preso à gaiola com uma tira elástica. Tanto as lagartas como os adultos foram mantidos em laboratório, com fotoperíodo aproximado de 12 horas e temperatura de $25-26^{\circ} \mathrm{C}$.

Os ovos depositados durante a noite, sobre o papel contínuo no interior das gaiolas ( $<12$ horas de idade), foram contados, e foram realizados recortes do papel, de modo a conter 15 ovos cada. Esses recortes de papel foram grampeados à primeira folha expandida do ápice das plantas, por meio da abertura lateral das gaiolas, onde permaneceram originando lagartas do curuquerê que foram monitoradas até a pupação ou morte de todas as lagartas.

As fases de pupa e de adulto foram também conduzidas em campo, por meio do confinamento de pupas após a sexagem sobre novas plantas, tendo sido empregadas as mesmas gaiolas descritas acima. Durante a fase de pupa, as gaiolas foram vistoriadas diariamente a partir do quinto dia de confinamento (o período pupal se dá de 8 a 12 dias, aproximadamente), para a constatação da emergência de adultos e, posteriormente, a intervalos de quatro dias, para se quantificar a produção de descendentes (ovos + lagartas), até a morte dos adultos. Assim que se formaram, 16 pupas foram coletadas ao acaso (oito casais por gaiolas por cultivar) e pareadas sobre novas plantas das respectivas cultivares de origem. As gaiolas onde ocorreu apenas a emergência de um indivíduo, independentemente do sexo, foram descartadas, em razão da necessidade de acasalamento para a produção de descendentes.

As condições de temperatura foram monitoradas a intervalos de $30 \mathrm{~min}$, com um chip WatchDog data log colocado no interior de uma das gaiolas, e temperatura média estimada para o período foi de $26,6^{\circ} \mathrm{C}$ (mínima de $22^{\circ} \mathrm{C}$ e máxima de $34,5^{\circ} \mathrm{C}$ ). Durante o período do estudo, não houve ocorrência de precipitação, e o fotoperíodo foi o natural para a região, que varia entre 12 e 13 horas de luz. As gaiolas foram identificadas com etiquetas de plástico colocadas em seu interior.

$\mathrm{O}$ efeito das cultivares de algodoeiro, sobre o desenvolvimento e a reprodução do curuquerê, foi 
estudado por meio das características de desenvolvimento e reprodução. A viabilidade dos ovos de laboratório, que originaram a infestação em campo, foi feita após quatro dias de sua introdução nas gaiolas, tendo-se recolhido os papéis que continham ovos e tendo-se feito a contagem dos ovos remanescentes. Simultaneamente, as posturas obtidas das gaiolas de criação, com mesmo número de repetições ( 8 por tratamento) e número de ovos (15 por repetição), foram mantidas em laboratório para correção da percentagem de eclosão, caso a viabilidade no campo fosse afetada por fatores abióticos e não de fertilidade. Nesse caso, as posturas monitoradas em laboratório eram acondicionadas em placas de Petri e mantidas a $25 \pm 1,8^{\circ} \mathrm{C}$, com fotoperíodo de 12 horas.

A determinação do período de duração da fase larval foi iniciada aos dez dias após a infestação das plantas com os ovos. A partir desse período, as gaiolas foram vistoriadas diariamente até a última pupa formada ou morte das lagartas. Em seguida, as pupas foram coletadas, pela retirada do pedaço de folha ou pela coleta das paredes das gaiolas, e conduzidas ao laboratório para pesagem e sexagem. Posteriormente, 16 pupas coletadas ao acaso, foram pareadas em casais e retornadas às gaiolas no campo, sobre novas plantas das respectivas cultivares de origem. Nessa ocasião foram avaliadas a duração e a viabilidade pupal. A oviposição e a longevidade dos adultos foram avaliadas em intervalos de quatro dias, quando foram colhidos os ponteiros das plantas com as gaiolas; em laboratório, foram quantificados a oviposição e o número de lagartas, bem como a mortalidade dos adultos. Antes da avaliação, os adultos, ainda vivos, foram coletados, transferidos para outras gaiolas e retornados ao campo.

Os dados obtidos de laboratório e campo foram submetidos ao teste de Kolmogorov e Barttlet, quanto à normalidade e homogeneidade de variância, respectivamente, e foram realizadas as transformações necessárias para atender aos requisitos da análise de variância (ANOVA). Em seguida, os resultados foram submetidos à análise de variância pelo PROC ANOVA do SAS Institute (2001), e as médias foram comparadas pelo teste de Tukey, a 5\% de probabilidade, quando significativas pela ANOVA.

$\mathrm{Na}$ avaliação de viabilidade de ovos, apenas um proveniente de campo e dois de laboratório não eclodiram. Portanto, não foram realizadas correções sobre a viabilidade de ovos a partir da viabilidade obtida em laboratório. A proporção de adultos sobreviventes, nas respectivas avaliações de quatro, oito e 12 dias após emergência, foi comparada entre as cultivares, pelo método Kaplan-Meier, por meio do PROC Lifetest do SAS Institute (2001). Com os resultados de desenvolvimento, sobrevivência e reprodução dos indivíduos criados em campo, foram estimados os parâmetros da tabela de vida de fertilidade (Maia et al., 2000). A partir da taxa intrínseca de crescimento populacional (r) e tempo médio (T) necessário para completar uma geração, nas condições do estudo, foi estimado o crescimento populacional, por meio do modelo geométrico ajustado da equação de Malthusian $\left(\mathrm{N}_{\mathrm{t}}=\mathrm{N}_{\mathrm{o}} \mathrm{e}^{\mathrm{rT}}\right)$, em que $\mathrm{N}_{\mathrm{t}}$ é o número de indivíduos produzidos, a partir do número de indivíduos que iniciam cada geração $\left(\mathrm{N}_{\mathrm{o}}\right)$, durante quatro gerações sucessivas. Apesar de $\mathrm{r}$ e $\mathrm{T}$ terem sido estimados com dados de campo, estes foram obtidos em gaiolas, portanto, fatores bióticos de mortalidade não foram considerados neste trabalho e, por isso, não foi usado o modelo logístico de crescimento populacional, que leva em consideração a resistência do ambiente promovida pelos fatores bióticos e abióticos de mortalidade impostos sobre a população.

\section{Resultados e Discussão}

Lagartas de A. argillacea completaram o desenvolvimento larval em diferentes períodos de tempo, quando alimentadas em laboratório com folhas das três cultivares de algodoeiro (Tabela 1). A cultivar BRS 201 proporcionou maior duração do período larval (14,4 dias), quando comparada às cultivares BRS Verde (11,7 dias) e Acala 90 (11,6 dias). Isto demonstra que a cultivar BRS 201 interferiu no desenvolvimento da fase larval de A. argillacea. Esse tipo de resposta é desejável em programas de manejo integrado de pragas que usam

Tabela 1. Duração, sobrevivência larval e peso de pupas de Alabama argillacea, alimentadas com folhas de três cultivares de algodoeiro, em laboratório. Temperatura de $25^{\circ} \mathrm{C}$, UR de $60 \%$ e fotoperíodo de 12 horas $^{(1)}$.

\begin{tabular}{lccc}
\hline Cultivar & \multicolumn{2}{c}{ Lagartas } & Peso de pupas \\
\cline { 2 - 3 } & Duração (dias) & Viabilidade (\%) & $(\mathrm{mg})$ \\
\hline BRS 201 & $14,2 \pm 0,34 \mathrm{a}$ & $46,0 \pm 6,96 \mathrm{~b}$ & $229,5 \pm 8,00 \mathrm{~b}$ \\
BRS Verde & $11,8 \pm 0,36 \mathrm{~b}$ & $76,0 \pm 7,77 \mathrm{a}$ & $253,6 \pm 3,37 \mathrm{a}$ \\
Acala 90 & $11,6 \pm 0,29 \mathrm{~b}$ & $84,0 \pm 7,18 \mathrm{a}$ & $252,9 \pm 6,35 \mathrm{a}$ \\
\hline $\mathrm{F}_{2,27}$ & $18,86^{* *}$ & $9,30^{* *}$ & $4,30^{*}$ \\
\hline
\end{tabular}

(1)Médias seguidas por letras iguais, na coluna, não diferem entre si pelo teste de Tukey, a 5\% de probabilidade. $*$ e $* *$ Significativo a 5 e $1 \%$ de probabilidade, respectivamente. 
materiais vegetais resistentes, pois o aumento da fase larval pode favorecer a ação de fatores de mortalidade, como inimigos naturais, visto que a lagarta ficará exposta por maior período de tempo e, além disso, completará menos gerações por ciclo fenológico do algodoeiro.

A viabilidade larval em laboratório também foi diferente entre as cultivares. As lagartas alimentadas com Acala 90 (84\%) e BRS Verde (76\%) não apresentaram diferença significativa. Porém, lagartas alimentadas com folhas da cultivar BRS 201 apresentaram apenas $46 \%$ de viabilidade (Tabela 1).

Observou-se, ainda, que lagartas criadas em plantas da cultivar BRS 201 originaram pupas significativamente menores, quando comparadas àquelas criadas nas demais cultivares (Tabela 1). No presente estudo, a área foliar consumida não foi medida. Portanto, o menor peso de pupa obtido com a cultivar BRS 201 pode ser relativo à não-preferência ou à ingestão de substâncias presentes nas folhas, que prejudicaram o desenvolvimento larval (antibiose), ou, ainda, relativo à ocorrência de ambos os fatores. De acordo com Ferreira \& Lara (1999), o genótipo CNPA 9211-31 além de promover prolongamento da fase larval de A. argillacea reduz a alimentação. Esse efeito de não-preferência quanto à alimentação, provavelmente, ocorreu com as lagartas que se alimentaram da cultivar BRS 201 sem chance de escolha, no entanto, esta hipótese necessita de outros estudos para confirmação.

O desenvolvimento e a reprodução de A. argillacea foram influenciados pelo tipo de alimento (cultivares de algodoeiro) que essa praga recebeu em campo (Tabela 2). Entre os parâmetros estudados, apenas a viabilidade das fases de ovo e larval não foi afetada pelo tipo de alimento. A cultivar BRS 201, como esperado a partir dos resultados de laboratório, proporcionou prolongamento de aproximadamente dois dias na fase larval, redução no peso de pupas e viabilidade da fase de pupa. Com relação à produção de descendentes, a cultivar Acala 90 proporcionou a maior produção de ovos e lagartas $(142,2 \pm 51,0)$, tendo diferido estatisticamente $\left(\mathrm{F}_{2,11}=4,49 ; \mathrm{p}=0,0376\right)$ das cultivares de fibra colorida BRS Verde $(27,8 \pm 15,1)$ e de fibra branca BRS $201(7,8 \pm 5,2)$.

A sobrevivência de adultos em campo foi afetada, conforme a cultivar de algodoeiro utilizada como hospedeira desde a fase de ovo. Adultos criados, oriundos de lagartas alimentadas pela cultivar BRS 201, viveram em média 5,5 dias, em comparação aos 7,5 e 7,8 dias de sobrevivência média para adultos obtidos de indivíduos criados e mantidos nas cultivares BRS Verde e Acala 90, respectivamente. Esta sobrevivência específica foi significativamente diferente entre as cultivares (Figura 1).

Em razão de o curuquerê ter sido afetado negativamente em relação ao peso, duração e viabilidade de pupas, da produção de descendentes e sobrevivência de adultos, quando criado na cultivar BRS 201, pode-se inferir que esta cultivar é menos suscetível à referida praga, em comparação às demais cultivares estudadas. Entre as variáveis estudadas, a viabilidade de pupa e a produção de descendentes foram as características mais afetadas (Tabela 2). Portanto, apesar de não serem características que reduziriam imediatamente as perdas provocadas na lavoura, em conseqüência da alimentação de lagartas de uma mesma geração, as gerações subseqüentes da praga serão afetadas e, também o seu crescimento populacional, como observado para a cultivar BRS 201, seguido pela BRS Verde, comparadas à cultivar Acala 90.

Tabela 2. Características do desenvolvimento de Alabama argillacea, confinada em plantas de algodoeiro de fibra branca ou colorida, em campo. Temperatura média do período de estudo no interior da gaiola de $26,6^{\circ} \mathrm{C}$ (mínima de $22^{\circ} \mathrm{C}$ e máxima de $34,5^{\circ} \mathrm{C}$ ) e fotoperíodo natural.

\begin{tabular}{|c|c|c|c|c|}
\hline \multirow[t]{2}{*}{ Característica } & \multicolumn{3}{|c|}{ Cultivares $^{(1)}$} & \multirow{2}{*}{$\begin{array}{c}\text { Estatística } \\
\mathrm{F}_{2,21}\end{array}$} \\
\hline & Acala 90 & BRS Verde & BRS 201 & \\
\hline Viabilidade da fase de ovo (\%) & $99,2 \pm 0,83 a$ & $100,0 \mathrm{a}$ & $100,0 \mathrm{a}$ & $1,00^{\mathrm{ns}}$ \\
\hline Duração da fase larval (dias) & $12,5 \pm 0,19 \mathrm{a}$ & $12,7 \pm 0,24 \mathrm{a}$ & $14,7 \pm 0,32 b$ & $20,70 * *$ \\
\hline Viabilidade da fase larval (\%) & $62,5 \pm 8,54 a$ & $66,6 \pm 10,30 \mathrm{a}$ & $76,6 \pm 5,34 a$ & $0,77^{\mathrm{ns}}$ \\
\hline Peso de pupas (O', mg) & $249,1 \pm 2,50 \mathrm{a}$ & $248,6 \pm 3,67 a$ & $217,6 \pm 4,47 b$ & $24,58 * *$ \\
\hline Peso de pupas $(\Varangle, \mathrm{mg})$ & $272,1 \pm 6,00 \mathrm{a}$ & $258,2 \pm 3,49 \mathrm{a}$ & $222,8 \pm 4,34 b$ & $28,76^{* *}$ \\
\hline Duração da fase de pupa (dias) & $7,1 \pm 0,26 \mathrm{a}$ & $7,4 \pm 0,40 \mathrm{a}$ & $8,6 \pm 0,62 \mathrm{a}$ & $3,55^{\mathrm{ns}}$ \\
\hline Viabilidade da fase de pupa (\%) & $81,2 \pm 13,15 \mathrm{a}$ & $62,5 \pm 18,29 \mathrm{ab}$ & $50,0 \pm 18,89 \mathrm{~b}$ & $8,16^{*}$ \\
\hline
\end{tabular}

${ }^{(1)}$ Médias seguidas por letras iguais, na linha, não diferem entre si pelo teste de Tukey, a $5 \%$ de probabilidade. ns Não-significativo. * e **Significativo a 5 e $1 \%$ de probabilidade. 
O número de indivíduos que atingem a fase adulta e o número de descendentes produzidos são os parâmetros que mais afetam a taxa líquida de reprodução $\left(R_{0}\right)$ e, conseqüentemente, o crescimento populacional de qualquer indivíduo medido pela taxa extrínseca de crescimento (r). Este é um resultado importante a ser considerado no manejo do curuquerê, já que essa é uma praga que pode colonizar a lavoura ainda jovem e completar várias gerações durante o seu ciclo. Considerando-se que os surtos populacionais de A. argillacea, acima do nível de controle, ocorrem somente após completarem uma ou mais gerações a partir da colonização da lavoura, o plantio da cultivar BRS 201 acarretará um crescimento populacional 44,6 e 180,9 vezes menor, após quatro gerações, a partir da colonização por uma fêmea fecundada, em comparação às cultivares BRS Verde e Acala 90, respectivamente (Figura 2). Assim, um maior número de gerações será

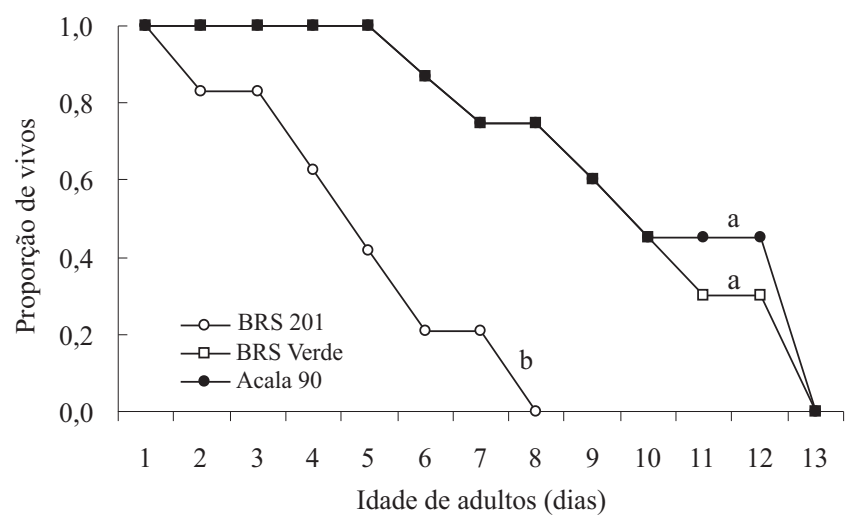

Figura 1. Sobrevivência de fêmeas de Alabama argillacea, criadas e confinadas em plantas de cultivares de algodoeiro de fibra branca ou colorida, em campo. Curva de sobrevivência com letras diferentes indica diferença na sobrevivência pelo teste $\log \operatorname{Rank}\left(\mathrm{GL}=2 ; \chi^{2}=17,17 ; \mathrm{P}=0,0002\right)$.

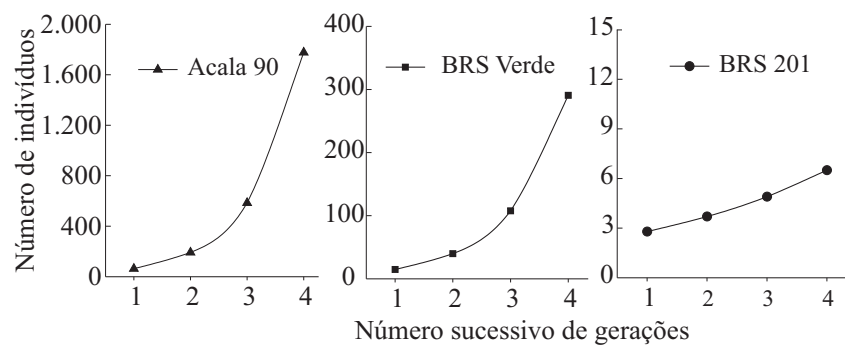

Figura 2. Estimativa do crescimento populacional de Alabama argillacea confinada, em campo, sobre plantas de algodão das cultivares Acala 90, BRS Verde e BRS 201, durante quatro gerações. necessário para produzir populações acima do nível de controle na cultivar BRS 201. Apesar de esta estimativa ter sido feita com base em dados de desenvolvimento e reprodução do curuquerê em campo, este experimento foi realizado com o confinamento de indivíduos em gaiolas, o que exclui a ação dos inimigos naturais. Os resultados obtidos por meio desta estimativa devem estimular futuros trabalhos que estudem os mecanismos que provocam a resistência da cultivar BRS 201 ao curuquerê, além de avaliações sobre variações na biologia e crescimento populacional dessa praga sob ação dos inimigos naturais.

\section{Conclusões}

1. Alabama argillacea, criada com folhas da cultivar de algodoeiro BRS 201, apresenta menor desenvolvimento, sobrevivência e reprodução, em comparação a lagartas criadas com folhas das cultivares BRS Verde e Acala 90.

2. O crescimento populacional, estimado por quatro gerações sucessivas de Alabama argillacea, é 44,6 e 180,9 vezes menor na cultivar de algodão BRS 201, em comparação às cultivares BRS Verde e Acala 90, respectivamente.

\section{Agradecimentos}

Ao Conselho Nacional de Desenvolvimento Científico e Tecnológico, por concessão de bolsas; à Fundação de Amparo à Ciência e Tecnologia do Estado de Pernambuco e à Financiadora de Estudos e Projetos, pelo apoio financeiro; à DuPont, pelo fornecimento das pupas de Alabama argillacea; à Monsanto S.A., pelo fornecimento das sementes de Acala 90; à Embrapa Algodão, pelo fornecimento das sementes de BRS Verde e BRS 201.

\section{Referências}

ARAÚJO, A.E.; SILVA, C.A.D.; FREIRE, E.C.; COSTA, J.N.; AMARAL, J.A.B.; MEDEIROS, J.C.; SILVA, K.L.; BARROS, M.A.L.; BELTRÃO, N.E.M.; SUASSUNA, N.D.; FIRMINO, P.T.; FERREIRA, P.F.; ALMEIDA, R.P.; SANTOS, R.F.; FREIRE, R.M.M.; PEREIRA, S.R.P. Cultura do algodão herbáceo na agricultura familiar. Campina Grande: Embrapa Algodão, 2003. Disponível em: http://sistemasdeproducao.cnptia.embrapa.br/ FontesHTML/Algodao/AlgodaoAgriculturaFamiliar/index.htm. Acesso em: 12 ago. 2006. 
BLEICHER, E. Resistência de genótipos de algodoeiro ao curuquerê, Alabama argillacea (Hübner, 1818) Lepidoptera Noctuidae. Anais da Sociedade Entomológica do Brasil, v.11, p.197-202, 1982.

BOTTRELL, D.G.; BARBOSA, P.; GOULD, F. Manipulating natural enemies by plant variety selection and modification: a realistic strategy? Annual Review of Entomology, v.43, p.347367, 1998.

CONAB. Avaliação da safra agrícola 2006/2007: quarto levantamento: janeiro/2007. Brasília: Ministério da Agricultura, Pecuária e Abastecimento, 2007. 22p.

DOMICIANO, N.L.; SANTOS, W.J. Momento adequado para aplicação de inseticida no controle do curuquerê-do-algodoeiro. Pesquisa Agropecuária Brasileira, v.29, p.7-11, 1994.

FERREIRA, A.; LARA, F.M. Tipos de resistência a Alabama argillacea (Huebner, 1818) (Lepidoptera: Noctuidae) envolvidos em genótipos de algodoeiro: II. Antibiose. Bragantia, v.58, p.287-292, 1999.

JORNAL DA ABRAPA. Brasília: Abrapa, v.81, 2007. 6p.

LARA, F.M.; FERREIRA, A.; CAMPOS, A.R.; SOARES, J.J. Tipos de resistência a Alabama argillacea (Huebner) (Lepidoptera: Noctuidae) envolvidos em genótipos de algodoeiro: I. Não-preferência. Anais da Sociedade Entomológica do Brasil, v.28, p.739-744, 1999.
MAIA, A.H.N.; LUIZ, A.J.B.; CAMPANHOLA, C. Statistical inference on associated fertility life table parameters using Jackknife technique: computational aspects. Journal of Economic Entomology, v.93, p.511-518, 2000.

QUIRINO, E.S.; SOARES, J.J. Efeito do ataque de Alabama argillacea no crescimento vegetativo e sua relação com a fenologia do algodoeiro. Pesquisa Agropecuária Brasileira, v.36, p.10051010, 2001.

RAMALHO, F.S. Cotton pest management: Part 4. A Brazilian perspective. Annual Review of Entomology, v.39, p.563-578, 1994.

SANTOS, T.M.; BOIÇA JÚNIOR, A.L. Resistência de genótipos de algodoeiro (Gossypium hirsutum L.) a Alabama argillacea (Hübner) (Lepidoptera: Noctuidae). Neotropical Entomology, v.30, p.297-303, 2001.

SAS INSTITUTE. SAS/STAT: user's guide: version 8.02: TS level 2MO. Cary: SAS Institute, 2001.

SOARES, J.J.; JÁCOME, A.G.; SOUSA, J.G.; OLIVEIRA, R.H.; WANDERLEY, D.S. Influência do desfolhamento simulado pelo ataque do curuquerê no desenvolvimento vegetativo e no rendimento do algodoeiro. Campina Grande: Embrapa Algodão, 1997. 6p (Comunicado técnico, 61).

SOARES, J.J.; SILVA, M.S. Efeito da época de plantio na produção e na ocorrência de pragas em culturas do algodoeiro (Gossypium hirsutum). Arquivos do Instituto Biológico, v.70, p.295-302, 2003. 